\title{
Informatization of the personal environment of students in Russia (on the materials of the research at the Bratsk State University)
}

\author{
Philipp Rozanov ${ }^{1, *}$, and Anastasia Rozanova ${ }^{1}$ \\ ${ }^{1}$ Bratsk State University, 665709, 40 Makarenko str., Bratsk, Russia
}

\begin{abstract}
Russia is on the way of radical changes in the political and economic sphere. One of the key directions of the country's transformation is the development of information and communication technologies and increasing the efficiency of their use. This determines the future place of Russia in the global system of Information Society. The article presents the results of a pilot sociological research of the level of informatization and informationalization of the personal environment of students in Russia. The basic statistical data on the technical, program and communication provision of the personal and working environment of students are analyse on the example of the Bratsk State University. Based on them are formulated conclusions about a high level of informatization in Russia, and rather low efficiency of using information and communication technologies. Was propose a hypothesis that a low level of informationalization is determined by the low level of relevant education and training.
\end{abstract}

\section{Introduction}

Modern civilization is on the way to the Information Society. This transition is accompanied by the rapid development of ICT (information and communication technologies) and their penetration into all spheres of people's lives. Computers, communication technologies and the Internet in developed countries have become commonplace and accessible to everyone. However, many researchers of the Information Society say that the informatization of society, that is, the widespread use of ICT, is not a determining factor in the transition to a new type of civilization. In their opinion, such a factor is informationalisation (Castells 1996) - the transition to the use of ICT for the production of information and knowledge [1,2].

Russia's transition to an information society is also accompanied by an intensive process of informatization of all spheres of life, the personal environment and work of people. Informatization of the economy, education, medicine and other industries is being actively investigated now. This is due to the interest in such monitoring of both business and government structures implementing national projects for the informatization of Russia. A

\footnotetext{
*Corresponding author: firoz@ ya.ru
} 
detailed analysis of the State Program of Informatization of Russia (in Russian: Государственная программа «Информационное общество») for 2011-2020 is presented on the portal of the Ministry of Communications of the Russian Federation [3]. At the same time, little attention is paid to the problem of studying the effectiveness of informatization, especially at the level of the personal environment of people.

The society becomes really "information" only in that case when information and communication technologies are no longer exotic and fun, but are an integral part of the functional environment of people. Therefore, the growth of informatization of the society in itself can not be an objective criterion for the transition to an information society. Important is the efficiency of the use of ICT - the ratio of the level of informatization and informationalization. Our long-term observations and analysis of scientific publications and media data make it possible to assume that now in Russia the growth of informatization of the personal environment of people is not accompanied by an adequate increase in the efficiency of ICT use, that is, informatization far outstrips the informationalization of personal environment.

\section{Research design}

To research this problem, we developed and conducted an appropriate sociological study. Since the most active and indicative social layer in the use of new information and communication technologies is youth, it was decided to conduct a study among university students. In order to be able to compare with the representatives of older age groups, students of the correspondence department and teachers were included in the general sample.

The problem underlying our research can be formulated as follows: the level of informationalisation of the student's personal environment lags far behind the level of its informatization and the efficiency of using ICT is quite low. By personal environment in this case, we mean the space of everyday life of students, including their technological environment at home, in an educational institution, at work and in the fields of recreation and communication. Under the informationalization of personal environment, we mean the use of available ICT with the highest possible efficiency, and first of all in the areas of processing and production of knowledge and information. Under the effective use of ICT, we mean the ratio between the possibilities of ICT and their actual level of use. With regard to the students' reality, this means the use of ICT for education, training and work.

The purpose of the research: to determine the level of informatization of the student's personal environment and to reveal the degree of its informationalization.

Object of the research: student and teaching staff of the Bratsk State University (Bratsk, Russia).

Subject of research: equipment of information and communication technologies of personal environment of students and the effectiveness of their use in everyday life.

Research hypothesis: the level of informatization of students' personal environment is high, but the efficiency of using ICT is extremely low, and the main reasons for the inefficient use of ICTs is lack of relevant knowledge and motivation.

To achieve this purpose, we have defined the following tasks:

1. Selection of criteria for informatization of personal environment.

2. Development of research methods.

3. Carrying out research of informatization and informationalization of students' personal environment and collection of statistical material.

4. Verification of the hypothesis at the relevant empirical data.

5. Interpretation of the results. 
The study was conducted on the basis of the Bratsk State University. The study population consisted of students of different courses. A representative sample of 400 people included students of all courses and all areas of study (humanitarian, technical and natural sciences) in equal proportions. In addition, a study was conducted among teachers and students of the correspondence department.

Unfortunately, in modern Russia the problem of informatization is not investigated enough. Although the technical development of information and communication technologies and their implementation in various spheres of life in Russia is quite active, the issues of the effectiveness of the organization of the personal information environment and the efficiency of ICT use fall out of the sphere of state interest. The scientific environment also gives insufficient attention to these issues. As a basis for assessing the informatization of personal environment, we took the guidance document of the Ministry of Communications and Information of the Russian Federation "Monitoring of Informatization in Russia. Main provisions of monitoring» (in Russian: “Мониторинг информатизации России. Основные положения мониторинга”) of 4 March 2002, № РД 115.005-2002 [4]. We adapted the provisions of this document to the research conditions and identified the following basic criteria of informatization of personal environment:

1. Availability of peripheral equipment (scanners, printers, graphics tablet, etc.).

2. Availability of Internet access (dial-up, broadband, permanent connection, etc.).

3. The quality of software (the number of licensed and unlicensed programs).

4. Availability of communication equipment (telephone, mobile phone, smartphone).

5. Availability of a television and radio.

To assess the level of informalization, we have chosen the following criteria:

1. Tasks for which ICT are used most often (games, education, work, multimedia, etc.).

2. Types of used software (multimedia, games, training, office, etc.).

3. Frequency of use of ICT (computer equipment, tele- and radio equipment, communication equipment).

4. The reasons that prevent the use of ICT more effectively.

The main method of collecting information was a questionnaire. Questions of the questionnaire were distributed among the blocks in accordance with the singled out criteria for informatization and informationalization, as well as additional questions about the sex, age, family and material situation. Since the study did not require knowledge of the respondents' personality, and to increase the objectivity of the answers, the survey was anonymous. Additional methods that increases the objectivity of the study were a conversation, a survey and included observation (students who observed their colleagues in natural conditions).

\section{Results}

During the study, 500 people were interviewed. Of these, a target group of full-time students of 400 people, teachers and students of the correspondence department of 100 people. Age of respondents ranged from 16 to 76 years. The average age of the target group is 21 years. The average age of the teaching staff and students in the correspondence department is 42 years. The study was carried out from 01.09.2016 to 01.11.2017.

We obtained the following data about informatization of personal environment:

1. $98 \%$ of respondents have a personal computer. Of the respondents own a stationary computer $89 \%$, laptops own $23 \%$, and the tablet has a $47 \%$. At the same time, $42 \%$ of respondents have a personal computer and a tablet, $18 \%$ have only a laptop, and $5 \%$ have a PC, a laptop and a tablet at the same time. 
2. Peripheral equipment is available in $67 \%$ of respondents. In $65 \%$ of cases it is a printer, $2 \%$ - only a scanner and $30 \%$ own an MFP.

3. Access to the Internet is available in $99.5 \%$ of respondents. Of these, permanent broadband access $73 \%$ access through mobile internet - $62 \%$. At the same time, $35.5 \%$ have simultaneously broadband Internet access and through cellular operators.

4. The situation with licensed software is ambiguous. In general, $85 \%$ of respondents have the licensed software. However, at the same time on the tablets, smartphones and phones licensed is $98 \%$ of the programs. On laptops, $89 \%$ of software is licensed, and only $67 \%$ of software is licensed on a PC. At the same time, $95 \%$ of respondents use these or other unlicensed programs. On mobile devices and laptops, almost all users have built-in licensed software. But on personal computers most of the licensed are only small programs, utilities and, in the first place, anti-virus software. Apparently, the software distribution model as a service and as an integral part of the hardware-software complex is more successful for software producers.

5. Means of communication have all respondents - 100\%. A stationary phone is available for $65 \%$, mobile for $100 \%$ (of which smartphones - 93\%). It is significant that in modern conditions, many fundamentally refuse to own a fixed telephone and have only a mobile phone.

6. $99 \%$ of respondents have a television at home, $64 \%$ of them are connected to cable TV, 55\% watch TV channels through the Internet.

7. $75 \%$ of respondents have radio receivers, of which $90 \%$ are multichannel.

The results of the questionnaire give the following picture of informationalization:

1. Respondents' answers to the question about what is most often used for a personal computer and a laptop are distributed as follows: multimedia $22 \%$, games $21 \%$, communication $3 \%$, education $17 \%$, work $14 \%$, creativity $1 \%$. Use of the tablet: multimedia $43 \%$, games $50 \%$, communication $3 \%$, creativity $2 \%$, education $1 \%$, work $1 \%$.

2. The means of communication (first of all, of course, a mobile phone and smartphone) are used most often for the following purposes: multimedia $31 \%$, games $28 \%$, communication $39 \%$, education $1 \%$, work $1 \%$.

3. Stationary Internet access is used most often for the following purposes: multimedia $32.5 \%$, games $35.5 \%$, communication $1.5 \%$, education $13 \%$, work $10 \%$, creativity $2.5 \%$, shopping $5 \%$. Mobile Internet access: multimedia $43.5 \%$, games $19.5 \%$, communication $32 \%$, education $3 \%$, work $1 \%$, creativity $0.5 \%$, shopping $0.5 \%$.

4. During the day, respondents spend an average of 2.5 hours on a stationary computer or laptop. If we talk about the time that respondents use to interact with smartphones, then for the majority this is a constant use during the day.

5. The software used by respondents: multimedia $89 \%$, games $72 \%$, training $53 \%$, office $48 \%$, Internet $39 \%$, professional $49 \%$.

6. Watching television is spent on average 2.5 hours per day. Talk show $21 \%$, documentary $6 \%$, news $15 \%$, scientific-cognitive $7 \%$, films and serials $34 \%$, musical $17 \%$.

7. On listening to the radio is spent on average 0.9 hours. Broadcasts, which respondents listen most often: news $16 \%$, entertainment $55 \%$, music $27.5 \%$, cognitive $1.5 \%$.

8. Among the reasons that prevented the use of ICT more efficiently, the respondents named the following main ones: lack of money $15 \%$, lack of time $20 \%$, laziness $10 \%$, lack of optimal conditions $15 \%$, none $40 \%$.

\section{Analysis of the research data}

Our research has fully confirmed the initial hypothesis. The level of informatization of students' personal environment is quite high. However, despite the high penetration of ICT 
into personal environment, the level of their use remains extremely low. Most of the students use computers for entertainment and games. Only 30\% use the computer for work and education. Educational software is only 55\% of PC users. In modern Russian realities, thanks to pirate activity, almost any more or less valuable software can be purchased for a minimum price or downloaded for free from file-sharing networks. Therefore, the lack of educational and professional software can be explained only by the lack of interest in it of themselves the respondents.

According to our observations, the main reasons for the low informationalization of students' personal environment are insufficient computer literacy, ignorance of the capabilities of modern ICTs and inability to use them. Many respondents have difficulty working with a word processor, not to mention about more complicated programs. The possibilities of technology are not using at full capacity. This applies and to personal computers and to smartphones. The search for information on the Internet occurs quite often, but is inefficient, because respondents do not have knowledge of search technologies and "Internet geography". The reasons for weak informationalization require a separate research. But apparently, the main problems are the low level of computer literacy and a weak motivation for mastering information technologies, caused by a lack of understanding of their capabilities and the role of ICT in modern society.

The research carried out by us is of a rather general and preliminary nature. Further research is required on the distribution of results by sex, age, level of education, social and economic status. Also is necessary to compare the results of the research with those of similar researches conducted in other cities and regions of Russia. However, regular monitoring of informatization and informationalization in the country is not is not conducting. Clear criteria and standards for such a research currently are not developed. To clarify this multifaceted problem is needed further scientific research, and to solve it is needed a purposeful state policy to increase information literacy and develop the culture of the information society. The success of Russia's transition to an information society depends on the degree of effectiveness of the use of the information and technological potential of the country. As well as from the degree of information literacy of people, and especially young people.

\section{References}

1. M. Castells, The rise of the network society, the information age: economy, society and culture (Blackwell, Oxford, 2009).

2. M. Castells, The Internet galaxy: reflections on the Internet, dusiness, and society. (Oxford University Press, Oxford, 2002)

3. Ministry of Digital Development, Communications and Mass Communications of the Russian Federation, The state program "Information Society" (2011-2020) (Government of Russia, Moscow, 2011)

4. Information Technology: monitoring of informatization in Russia (Moscow, 2018) 